\title{
Kainic Acid on Neostriatal Neurons Intracellularly Recorded in vitro: Electrophysiological Evidence for Differential Neuronal Sensitivity
}

\author{
Paolo Calabresi, Marco De Murtas, Nicola B. Mercuri, and Giorgio Bernardi \\ Clinica Neurologica, $2^{a}$ Università di Roma, 00173 Rome, Italy
}

The electrophysiological effects produced by different concentrations of kainic acid (KA) were studied by utilizing intracellular recordings from neostriatal slices. In most of the recorded cells $(81 \%)$, concentrations of $K A$ ranging between 10 and $300 \mathrm{nM}$ produced reversible and dose-dependent membrane depolarizations. Higher concentrations of this agonist caused larger depolarizations and changes of the membrane properties of the recorded neurons not reversible during the time of recording. In a smaller percentage ( $19 \%)$ of the recorded cells, 10-100 nM KA did not produce significant membrane depolarizations; in these neurons, the depolarizations produced by higher concentrations of KA were small and reversible. The 2 populations of neurons showed similar electrophysiological properties and did not reveal differential sensitivity to quisqualic acid (QUIS; 10$30 \mu \mathrm{M}$ ) or to NMDA (10-30 $\mu \mathrm{M})$. Tetrodotoxin (TTX; $1 \mu \mathrm{M}$ ) did not reduce the depolarizations produced by KA and by NMDA. Low-calcium, cobalt-containing solutions abolished the offects produced by NMDA, but not the KA-induced depolarizations. Kynurenic acid (500 $\mu \mathrm{M})$ significantly antagonized the depolarizations produced by KA and reduced the changes of the membrane properties caused by high doses of this agonist. In several neurons, KA induced bicuculline-sensitive synaptic depolarizing potentials. Our findings suggest the presence of 2 subpopulations of neostriatal neurons showing differential postsynaptic sensitivity to KA. The differential sensitivity of neostriatal neurons to KA might influence the responses of these cells to glutamatergic cortical inputs and the degenerative changes observed in neostriatal neurons in some pathological conditions.

Coyle and Schwarcz (1976) first described the neurotoxic consequences of direct infusion of the potent glutamate analog kainic acid (KA) in the rat neostriatum. The injection of KA caused a selective degeneration of neurons with cell bodies intrinsic to the striatum, but spared extrinsic axons passing through or terminating in the region (Coyle et al., 1978). The investigation of the neurotoxic effects of KA was prompted by the interest in the development of an animal model for Huntington's disease: Numerous neurochemical and histologic parallels have been demonstrated between the striatal lesions in the experimental animal and Huntington's disease (Coyle and Schwarcz, 1976;

\footnotetext{
Received May 25, 1990; revised Aug. 14, 1990; accepted Aug. 20, 1990.

We wish to thank Giuseppe Gattoni and Massimo Tolu for their excellent technical assistance. The work was supported by a CNR grant, "Prog. Fin. Chimica

Fine II," to G.B. and by CNR Grant 890347474 to P.C.

Correspondence should be addressed to Dr. Paolo Calabresi, Clinica Neurologica, Dip. Sanita, $2^{a}$ Università di Roma, Via O. Raimondo 00173, Rome, Italy.

Copyright (C) 1990 Society for Neuroscience $0270-6474 / 90 / 123960-10 \$ 03.00 / 0$
}

McGeer and McGeer, 1976; Ferrante et al., 1985). More recently, it has been shown that several other potent excitatory analogs of glutamate also exhibited selective neuronal toxicity after intracranial injection (Kohler and Schwarcz, 1983; Beal et al., 1986, 1989; Koh et al., 1986; Koh and Choi, 1988; Coyle, 1987). Identification of receptor subtypes for excitatory aminoacids differentially sensitive to specific agonists [NMDA, quisqualic acid (QUIS), and KA] provided the explanation of the differential patterns of neurotoxicity following the application of these excitotoxins (Mayer and Westbrook, 1987b; Choi, 1988; Monaghan et al., 1989; Wroblewski and Danysz, 1989). A striking aspect of the neurotoxic effects of $\mathrm{KA}$ is the marked variation in neuronal vulnerability: Some neurons in close proximity to the injection site were spared, whereas other neurons, in several cases distant from the primary lesion, were degenerated (Coyle el al., 1978; Coyle, 1983). More recently, a differential vulnerability of central neurons to neurotoxins interacting with NMDA and QUIS receptors has also been reported (Kohler and Schwarcz, 1983; Beal et al., 1986, 1989; Koh et al., 1986; Koh and Choi, 1988; Choi, 1988). These results are consistent with the increasing evidence that the excitotoxins acting at amino acid receptor subtypes have differential effects on neostriatal cells and on other central neurons (Garthwaite and Garthwaite, 1984; Araki et al., 1985; Ben-Ari, 1985; Koh et al., 1986; Coyle, 1987; Choi, 1988; Monaghan et al., 1989; Wroblewski and Danysz, 1989).

Previous in vivo studies have suggested a close correlation between the neurophysiologic potency and the neurotoxic effects of glutamate analogs when injected into the rat neostriatum (Schwarcz et al., 1978; Zaczek and Coyle, 1982). The limits of the in vivo methods did not allow the exact quantification of the potency of different excitotoxins on single neurons and the study of the pre- and/or postsynaptic mechanisms underlying the differential sensitivity of neostriatal neurons to glutamate analogs. By using intracellular recordings in vitro from neostriatal neurons, we have analyzed the electrophysiological effects of known concentrations of KA on these cells. Two groups of neostriatal neurons showing differential postsynaptic sensitivity to KA were characterized.

\section{Materials and Methods}

Male Wistar rats, weighing 150-200 gm, were used for the experiments. The preparation and maintenance of the slices have been described previously (Calabresi et al., 1987a,b, 1988, 1989a, 1990b). Briefly, coronal slices $(200-300 \mu \mathrm{m})$ were prepared from tissue blocks of the brain with the use of a vibratome while the tissue was moistened continuously with oxygenated $\left(95 \% \mathrm{O}_{2}, 5 \% \mathrm{CO}_{2}\right) \mathrm{Krebs}-$ Ringer solution at $36^{\circ} \mathrm{C}$.

These coronal slices $(200-300 \mu \mathrm{m})$ included the neostriatum, neocortex, and corpus callosum. A single slice was transferred to a recording chamber (vol, $0.5 \mathrm{ml}$ ) and submerged in continuously flowing Krebs solution $\left(36^{\circ} \mathrm{C}, 2-3 \mathrm{ml} / \mathrm{min}\right)$ gassed with $95 \% \mathrm{O}_{2}$ and $5 \% \mathrm{CO}_{2}$. 
Table 1. Physiological and pharmacological characteristics of the 2 subpopulations of neurons showing differential sensitivity to KA

\begin{tabular}{|c|c|c|c|c|c|c|c|c|}
\hline Type of neuron & $\begin{array}{l}\text { Membrane } \\
\text { potential } \\
(\mathrm{mV})\end{array}$ & $\begin{array}{l}\text { Membrane } \\
\text { resistance } \\
(\mathrm{M} \Omega)^{a}\end{array}$ & $\begin{array}{l}\text { Cells } \\
\text { showing } \\
\text { rectification } \\
(\%)^{b}\end{array}$ & $\begin{array}{l}\text { Cells spon- } \\
\text { taneously } \\
\text { firing } \\
(\%)^{c}\end{array}$ & $\begin{array}{l}\text { Cells } \\
\text { tonically } \\
\text { firing } \\
(\%)^{d}\end{array}$ & $\begin{array}{l}\text { Response to } \\
10 \mu \mathrm{M} \text { QUIS } \\
(\mathrm{mV})\end{array}$ & $\begin{array}{l}\text { Response to } \\
10 \mu \mathrm{M} \\
\text { NMDA } \\
(\mathrm{mV})\end{array}$ & $\begin{array}{l}\text { Response to } \\
30 \mu \mathrm{M} \text { NMDA } \\
(\mathrm{mV})\end{array}$ \\
\hline $\begin{array}{l}\text { High sensitivity to } \mathrm{KA} \\
\quad(81 \% ; n=52)\end{array}$ & $\begin{array}{l}-79.8 \pm 2 \\
(n=52)\end{array}$ & $\begin{array}{l}37 \pm 6 \\
(n=24)\end{array}$ & $\begin{array}{l}100 \\
(n=24)\end{array}$ & $\begin{array}{l}0 \\
(n=52)\end{array}$ & $\begin{array}{l}100 \\
(n=52)\end{array}$ & $\begin{array}{l}22 \pm 8 \\
(n=10)\end{array}$ & $\begin{array}{l}15 \pm 4 \\
(n=9)\end{array}$ & $\begin{array}{l}25 \pm 6 \\
(n=10)\end{array}$ \\
\hline $\begin{array}{l}\text { Low sensitivity to } \mathrm{KA} \\
\qquad(19 \% ; n=12)\end{array}$ & $\begin{array}{l}-79.6 \pm 3 \\
(n=12)\end{array}$ & $\begin{array}{l}38 \pm 7 \\
(n=8)\end{array}$ & $\begin{array}{l}100 \\
(n=8)\end{array}$ & $\begin{array}{l}0 \\
(n=12)\end{array}$ & $\begin{array}{l}100 \\
(n=12)\end{array}$ & $\begin{array}{l}22 \pm 7 \\
(n=4)\end{array}$ & $\begin{array}{l}14 \pm 5 \\
(n=4)\end{array}$ & $\begin{array}{l}28 \pm 6 \\
(n=4)\end{array}$ \\
\hline
\end{tabular}

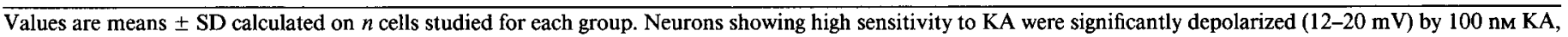
while cells showing low sensitivity to $\mathrm{KA}$ did not respond to this concentration of KA.

"Membrane resistance was measured by injecting hyperpolarizing current pulses of long duration and low intensity (200-800 msec, $0.1 \_0.3 \mathrm{nA}$, respectively).

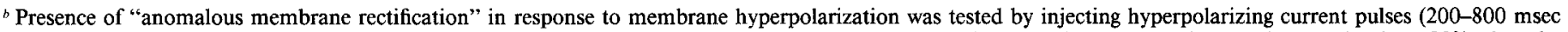

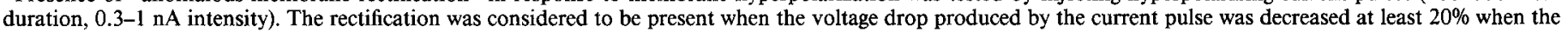
neuron was held at a membrane potential $25 \mathrm{mV}$ more negative than the resting level (see Calabresi et al., 1990 a,b).

c Percent of spontaneously firing neurons at resting level.

${ }^{d}$ The presence of tonic firing activity was studied by injecting depolarizing current pulses ( $200-800 \mathrm{msec}$ duration, $0.8-1.5 \mathrm{nA}$ intensity).

The composition of the solution was (in $\mathrm{mm}$ ) $126 \mathrm{NaCl}, 2.5 \mathrm{KCl}, 1.2$ $\mathrm{NaH}_{2} \mathrm{PO}_{4}, 1.2 \mathrm{MgCl}_{2}, 2.4 \mathrm{CaCl}_{2}, 11$ glucose, and $25 \mathrm{NaHCO}_{3}$. $\mathrm{NaH}_{2} \mathrm{PO}_{4}$ was omitted when solutions contained cobalt.

Intracellular recording electrodes were filled with $2 \mathrm{M} \mathrm{KCl} \mathrm{(30-60}$ $\mathrm{M} \Omega$ ).

Intracellular potentials were recorded with the use of an Axoclamp 2-A amplifier, displayed on an oscilloscope, and stored on a digital system. The statistical significance of the experiments was evaluated with the use of a Student's $t$ test.

Drugs were applied by dissolving them to the desired final concentration in the saline and by switching the perfusion from control saline to drug-containing saline. New solutions entered in the recording chamber within $20 \mathrm{sec}$. The following drugs were applied: bicuculline, kainic acid, kynurenic acid, NMDA, quisqualic acid, and tetrodotoxin (TTX; all from Sigma).

\section{Results}

\section{General characteristics of the recorded cells}

The results are based on intracellular recordings from 70 neostriatal neurons. Although no intracellular staining of these neurons was attempted in this study, it is probable that most impaled cells were medium spiny neurons because other studies reported that the majority of intracellularly stained cells in the neostriatum were of this type (Preston et al., 1980; Wilson and Groves, 1980; Lighthall and Kitai, 1983; Misgeld et al., 1984; Kawaguchi et al., 1989). Intrinsic membrane properties of these cells have been previously described both in vivo (Preston et al., 1980; Calabresi et al., 1990a) and in vitro (Kita et al., 1984; Calabresi et al., 1987a,b, 1988, 1990b) preparations. The cells included in the data were selected on the basis of having a stable resting membrane potential of at least $-70 \mathrm{mV}$, a spike amplitude of $>80 \mathrm{mV}$, a spike overshoot of $20-30 \mathrm{mV}$, and an action potential duration of less than $1.5 \mathrm{msec}$.

\section{Action of KA: comparison with NMDA and QUIS}

As shown in Figure $1 A$, in most of the recorded neurons, 100 nM $\mathrm{KA}$ in the perfusion medium produced membrane depolarizations ranging between 12 and $20 \mathrm{mV}$. Usually, the KAinduced depolarization did not trigger action potentials. A smaller percentage of neurons did not show membrane-potential changes during perfusion of the slice with this concentration of KA (Fig. $1 B$ ). Application of NMDA (10-30 $\mu \mathrm{M})$ or QUIS (10-30 $\mu \mathrm{M})$ in the perfusion medium caused significant and dose-dependent depolarizations in all the tested neurons (see Fig. 1, Table 1). Membrane depolarizations produced by KA were slower than those caused by NMDA or QUIS. In contrast to KA and QUIS,
NMDA induccd bursts of action potentials during membrane depolarizations. Membrane hyperpolarizations by negative holding current reduced or abolished the amplitude of the NMDA-induced depolarizations, but not those caused by KA and QUIS (not shown). In some cells, the depolarizations induced by QUIS were followed by a membrane hyperpolarization (Fig. 1). This event was never observed following application of KA or NMDA. Repeated applications of the 3 different agonists for the excitatory amino acid receptors showed that the desensitization following prolonged application of KA was longer (5-19 $\mathrm{min})$ than those observed following application of QUIS and of NMDA (1-3 min).

\section{Dose-response curves for $K A$}

In order to quantify the differential sensitivity of the recorded cells to $\mathrm{KA}$, we studied the dose-response relation for this agonist in several neostriatal neurons. As shown in Figure $2 A$, in most of the recorded cells, $10 \mathrm{nM} \mathrm{KA}$ was sufficient to cause small, but significant, membrane depolarizations (see also Fig. 3). In these cells, higher concentrations of KA (30-300 nM) induced larger reversible and dose-related membrane depolarizations (Figs. 2A, 3).

The increase of the KA concentration up to $1 \mu \mathrm{M}$ caused dramatic neuronal depolarizations not reversible during the time of recording (Fig. 2Ac). Spontaneous depolarizing potentials, usually observed during application of a lower concentration of KA in these cells, were transiently increased in amplitude and frequency in the early phase of the depolarization produced by high doses of KA, but they were completely suppressed after this transient increase (Fig. 2A). The minority of the recorded cells, which did not produce significant membrane responses to 10-100 nM KA, was only slightly depolarized by $300 \mathrm{~nm} \mathrm{KA}$ (Fig. $2 B$ ). In these cells, higher doses of KA (1-3 $\mu \mathrm{M})$ induced larger membrane depolarizations, but did not cause dramatic changes of the intrinsic propertics of the ncurons. Spontaneous depolarizing potentials were usually observed in these cells during applications of 0.3-1 $\mu \mathrm{M} \mathrm{KA}$ (Fig. 2B). Cumulative doseresponse curves for the effects produced by $\mathrm{KA}$ in the 2 groups of neurons are shown in Figure 3.

Membrane properties of these 2 subpopulations of cells showing differential sensitivity to KA are summarized in Table 1 . Membrane potential and membrane resistance were similar in these 2 groups of neurons. The 2 subpopulations of cells showed 
A

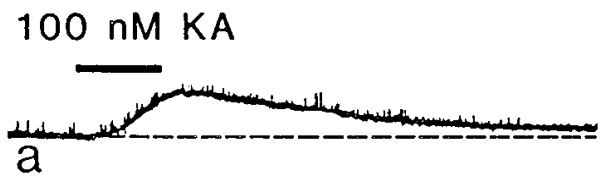

Figure 1. Electrophysiological action of KA, NMDA, and QUIS in 2 different neostriatal neurons. $A$, In this cell, 100 пм $K A$ produced a slow membrane depolarization (a), $10 \mu \mathrm{M} N M D A$ caused a membrane depolarization coupled with the activation of action-potential discharge $(b)$, and $10 \mu \mathrm{M}$ QUIS produced a relatively fast membrane depolarization followed by a hyperpolarization and a rebound depolarization (c). $B$, In another cell, $100 \mathrm{~nm} K A$ did not cause significant membrane potential changes $(a) ; 10 \mu \mathrm{M} N M D A(b)$ and $10 \mu \mathrm{M} Q U I S(c)$ produced membrane effects similar to those observed in the cell shown in $A$. Resting membrane potential (RMP) was similar in both these cells ( $-80 \mathrm{mV}$; broken line). In $A b$ and $B b$, the amplitude of the fast transients was not fully reproduced due to the limited frequency response of the pen recorder. Calibration bars apply to both $A$ and $B$. Horizontal bars indicate the period of application of the drugs.

Figure 2. Membrane potential changes induced by various concentrations of $\mathrm{KA}$ in 2 neostriatal neurons showing differential sensitivity to this glutamate analog. $A$, In this neuron, low concentrations of KA $(a, 10 \mathrm{nM} ; b, 100 \mathrm{nM})$ induced dose-dependent and reversible membrane depolarization; in the same cell, a high concentration of $\mathrm{KA}(1 \mu \mathrm{M})$ caused large and irreversible membrane depolarization $(c)$. Note the transient increase of spontaneous depolarizing potentials in the early phase of the depolarization caused by $1 \mu \mathrm{M}$ KA. $B$, In another neostriatal neuron, $30 \mathrm{~nm}(a)$ and $100 \mathrm{~nm}(b)$ did not cause significant potential changes; a slight membrane depolarization was observed in the presence of $300 \mathrm{nM} \mathrm{KA}(b)$; in this cell, a high concentration of KA $(1 \mu \mathrm{M})$ produced significant, but reversible, membrane depolarization $(c)$. Note the increased frequency of spontaneous depolarizing potentials in the presence of $300 \mathrm{nM}$ to $1 \mu \mathrm{M} \mathrm{KA}(b, c)$. RMP was similar in both these cells $(-78 \mathrm{mV})$. Calibration bars apply to both $A$ and $B$.
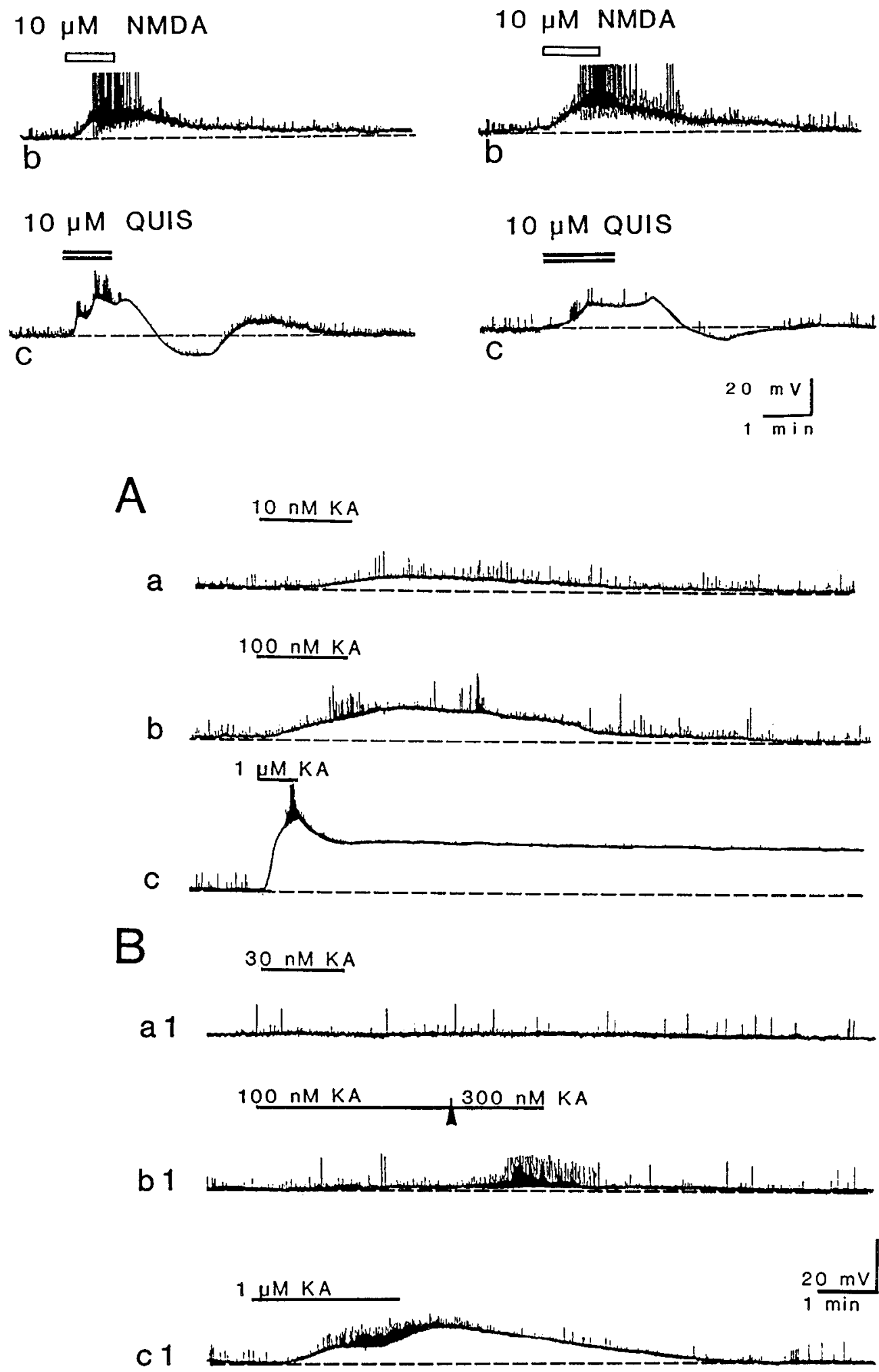


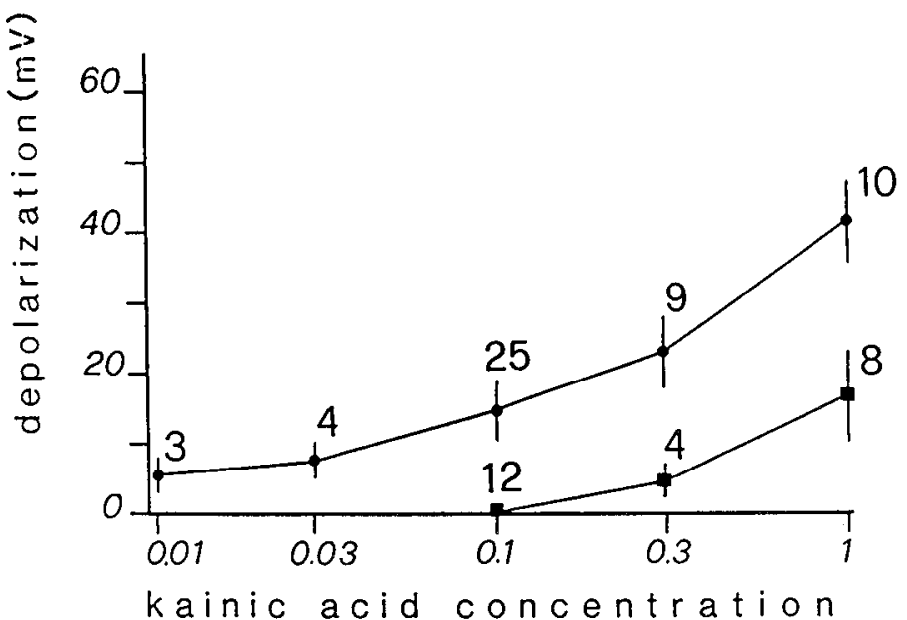

$(\mu \mathrm{M})$

Figure 3. Concentration-response curves for membrane depolarizations caused by KA in 2 neuronal subpopulations showing differential sensitivity to this drug. (RMP, between -75 and $-82 \mathrm{mV}$ ). The circles indicate cells showing high sensitivity to KA, while the squares represent neurons showing low sensitivity to this glutamate analog. Each point shows mean effects, and vertical lines indicate SEM for the numbers of neurons indicated.

electrophysiological characteristics similar to those previously described in other reports (Kita et al., 1984; Calabresi et al., 1987a,b, 1988, 1989b, 1990b; Kawaguchi et al., 1989): presence of membrane rectification at hyperpolarized levels of membrane potential, absence of spontaneous action potentials at rest, and tonic firing evoked by depolarizing current pulses without prominent accommodation.

\section{Action of $K A$ on membrane resistance and current-evoked firing}

The effects of KA on membrane resistance and on currentevoked firing were fully investigated only in cells showing high sensitivity to KA. As shown in Figure $4 A$, membrane resistance decreased during large depolarizations produced by high $(0.3-$ $1.0 \mu \mathrm{M})$ concentrations of KA. The KA-induced decrease of resistance persisted when the membrane was manually clamped at resting level by injecting negative current through the recording electrode (Fig. 4B). Depolarizing current pulses, which under the control condition triggered trains of action potentials, failed to produce spikes during applications of high doses of $\mathrm{KA}$; the decrease of the membrane resistance and of the firing frequency outlasted for several minutes the application of KA and, in several cells, was not reversible during the time of the recording (Fig. 4).

The effects of lower concentrations of KA (10-100 nM) were more complex. In most of the cells (14/24), these doses of KA decreased membrane resistance. In some neurons $(6 / 24)$, during membrane depolarizations induced by low concentrations of $\mathrm{KA}$, an apparent increase of the membrane resistance was observed. However, when the membrane was manually clamped to the resting level to avoid the influence of membrane rectification, the resistance increase was abolished. In a few cells (4) 24), the increase of the resistance persisted during the manual clamp of the membrane. In these neurons, the frequency of action potentials evoked by depolarizing current pulses was increased by KA (Fig. 5).

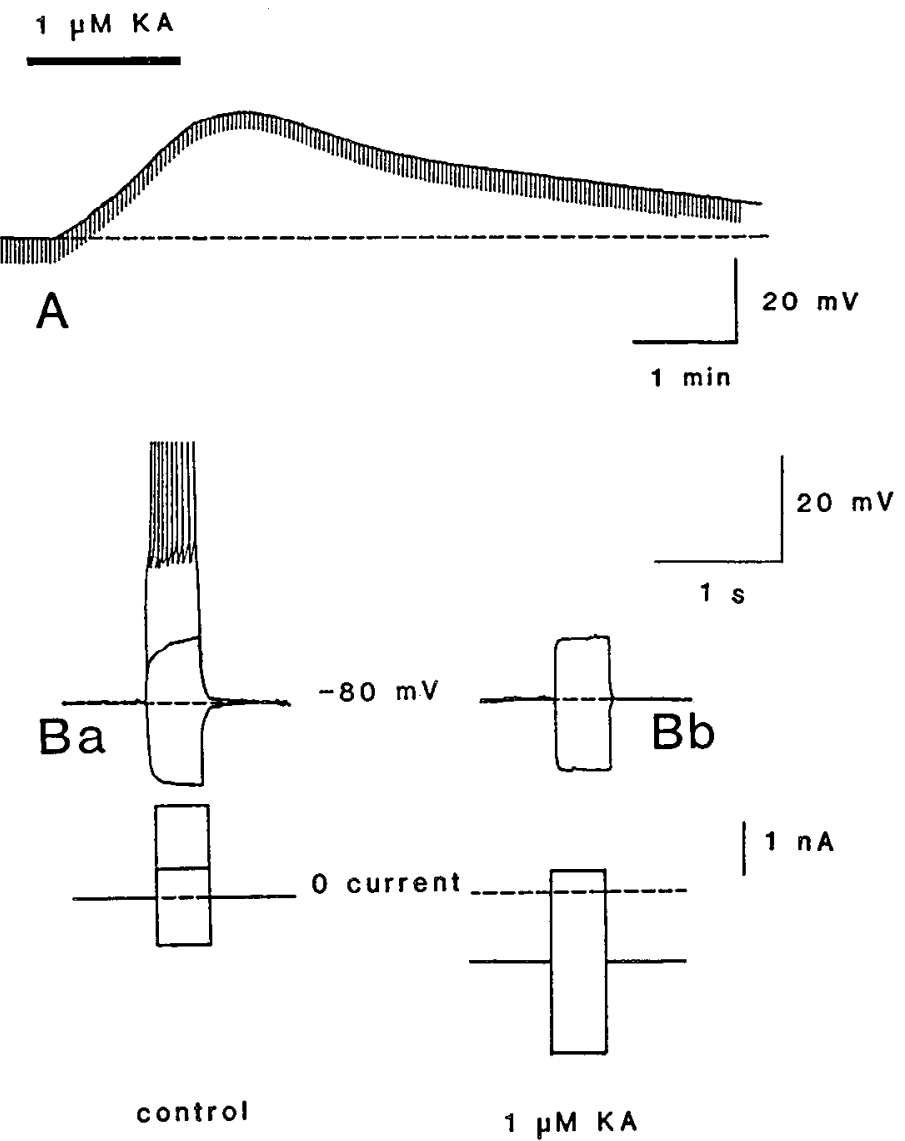

Figure 4. Changes of membrane conductance and current-evoked firing frequency produced by high concentration of KA. A, Application of $\mathrm{KA}(1 \mu \mathrm{M})$ induced a large membrane depolarization coupled with a decrease of the membrane resistance as shown by the reduction of the amplitude of the voltage drops (downward deflections) generated by hyperpolarizing current pulses ( $500 \mathrm{msec}$ duration, $0.2 \mathrm{nA}$ intensity). The broken line indicates the RMP $(-79 \mathrm{mV})$; note that the membrane potential did not fully recover after the application of $1 \mu \mathrm{M} \mathrm{KA} . B a$, In another neostriatal neuron, in the control condition, depolarizing current pulses of different intensities evoked either a subthreshold voltage response or a tonic firing discharge, while a pulse of negative current generated a hyperpolarizing voltage response. $B b$, In the presence of 1 $\mu \mathrm{M} \mathrm{KA}$, the membrane was manually clamped to the resting level $(-80$ $\mathrm{mV}$; broken line in upper trace) by injecting constant negative current through the recording electrode (broken line in lower trace indicates 0 current). Note that, in the presence of $1 \mu \mathrm{M} \mathrm{KA}$, the depolarizing current pulse did not trigger any more action potentials, and a much higher intensity of negative current was required to obtain a hyperpolarizing voltage response similar to that observed in control condition.

\section{$T T X$ and low-calcium, cobalt-containing solutions}

Pre- and postsynaptic mechanisms have been postulated to explain the physiological responses and the toxicity induced by KA in central neurons (McGeer et al., 1978; Ferkany et al., 1982; Ben-Ari, 1985; Greenamyre and Young, 1989). For this reason, the action of this agonist was studied either in TTX or in low-calcium, cobalt-containing solutions to block synaptic transmission. In 5 of 5 experiments, TTX $(1 \mu \mathrm{M})$ affected neither the depolarizations produced by different concentrations of KA nor those caused by 10-30 $\mu \mathrm{M}$ NMDA or QUIS (Fig. 6A-C). TTX also failed to block the depolarizations induced by high doses of KA (1-3 $\mu \mathrm{M})$ in neurons showing low sensitivity to KA (data not shown). 

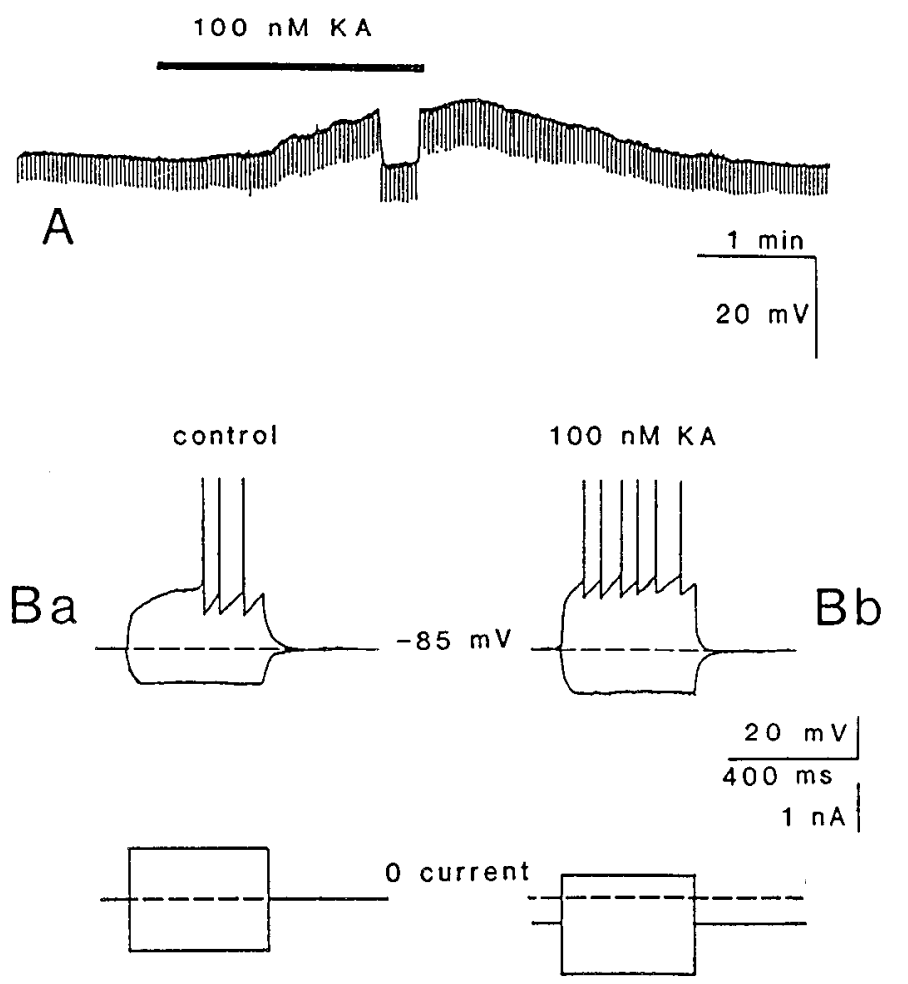

Figure 5. Increase of membrane resistance and current-evoked firing frequency by low doses of KA. $A$, In some neurons, membrane depolarization, caused by low doses of KA (100 nM), is coupled with an apparent increase of the membrane resistance, as shown by the amplitude of the voltage drops (downward deflections) generated by hyperpolarizing current pulses ( $500 \mathrm{msec}$ duration, $0.15 \mathrm{nA}$, intensity). Note that the KA-induced increase of the membrane resistance persists even during manual clamp of the membrane at resting level $(-83 \mathrm{mV}), B a$, In another neostriatal neuron, under the control condition, a depolarizing current pulse produces action potentials, while a negative current pulse causes a hyperpolarizing response. $B b$. In the presence of $100 \mathrm{nM}$ $\mathrm{KA}$, the firing frequency is increased, and the amplitude of the voltage drop produced by negative current is augmented, suggesting that, in this cell, $\mathrm{KA}$ increases membrane resistance. Note that, in the presence of $\mathrm{KA}$, the membrane is held at resting level $(-85 \mathrm{mV})$ by constant negative current.

In TTX-containing medium, NMDA produced regenerative all- or-none plateau potentials (300-800 msec duration; $25-50$ $\mathrm{mV}$ amplitude); the threshold for the generation of these potentials $(-40$ to $-50 \mathrm{mV})$ was higher than the level for the activation of TTX-sensitive spikes (Fig. $6 B, D$ ). The characteristics of these regenerative potentials resembled those previously described for calcium-mediated plateau potentials (Misgeld et al., 1986; Calabresi et al., 1987a).

In 6 of 6 experiments low-calcium $(0.5 \mathrm{~mm})$, cobalt-containing $(1.5 \mathrm{mM})$ solutions abolished the depolarizations induced by NMDA, but not those produced by KA (Fig. 7).

\section{Antagonism by kynurenic acid}

Although it has been widely shown that physiological responses induced by $\mathrm{KA}$ and other excitatory amino acids are blocked by specific antagonists, nonspecific mechanisms have also been implicated in the excitotoxic effect produced by KA in central neurons (Ben-Ari, 1985; Coyle, 1987). In order to test this hypothesis, we studied the effect of kynurenic acid on the depolarizations produced by different concentrations of KA. As shown in Figure 8, $500 \mu \mathrm{M}$ kynurenic acid clearly reduced the effects
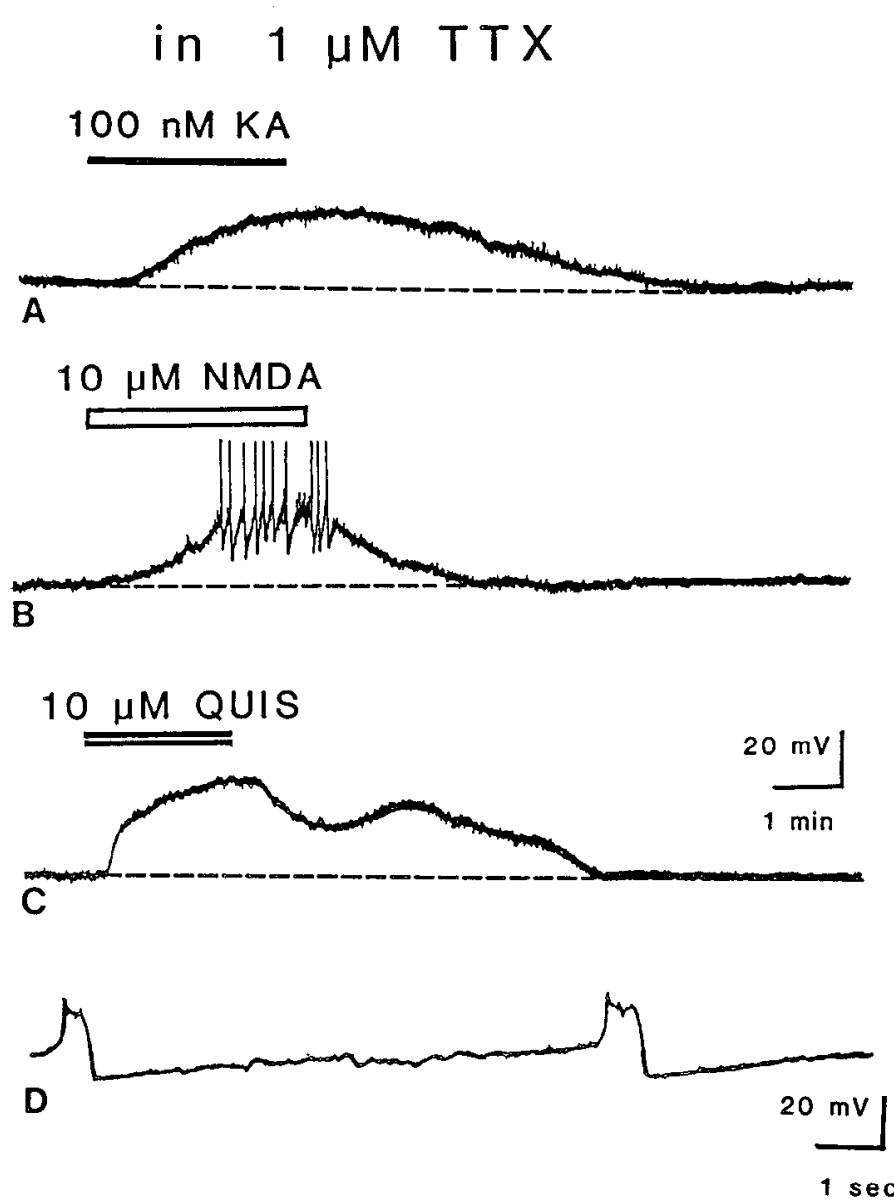

Figure 6. Membrane responses to KA, NMDA, and QUIS persist in presence of TTX. All traces were recorded from the same neostriatal neuron in the presence of $1 \mu \mathrm{M}$ TTX. $A$, One hundred nм $K A$ produced a slow depolarization. $B$, Ten $\mu \mathrm{M} N M D A$ induced a membrane depolarization that triggered several all-or-none plateau potentials. $C$, Ten $\mu \mathrm{M} Q U I S$ evoked a relatively fast membrane depolarization. $D$, TXXresistant plateau potentials induced by $10 \mu \mathrm{M}$ NMDA are shown at higher speed. RMP, $-74 \mathrm{mV}$. Calibration bars in $C$ apply to $A-C$.

caused by 100 nM KA. This concentration of kynurenic acid was also able to greatly decrease the depolarizations induced by high doses of $\mathrm{KA}(1 \mu \mathrm{M})$. In 3 cells, the effects of $1 \mu \mathrm{M} \mathrm{KA}$ were studied during kynurenate applications and at different times from the onset of washout of this antagonist (Fig. 8D); 15-20 min after the onset of the wash, $1 \mu \mathrm{M} \mathrm{KA}$, which during kynurenate application produced only reversible effects, caused large depolarizations coupled with permanent changes of the membrane properties of the neurons (Fig. 9).

\section{$K A$ induces spontaneous bicuculline-sensitive depolarizing potentials}

In several neurons, during the application of KA, spontaneous depolarizing potentials were observed. These spontaneous potentials were greatly reduced by TTX and completely abolished by low-calcium, cobalt-containing solutions (Fig. 7). The appearance of these potentials was more evident in the group of cells showing low postsynaptic sensitivity to KA during applications of high concentrations $(0.3-1 \mu \mathrm{M})$ of KA. In these cells, KA produced bursts of these spontaneous depolarizing potentials. As shown in Figure 10,100 $\mu \mathrm{M}$ bicuculline reduced the 
amplitude and the frequency of these KA-induced spontancous potentials. Bicuculline-sensitive potentials were depolarizing, even at depolarized membrane potentials, because the electrodes contained $\mathrm{KCl}$.

\section{Discussion}

The major findings in the present study can be summarized as follows. First, 2 subpopulations of cells showing differential sensitivity to KA, but not to QUIS and NMDA, are recorded in neostriatal slices; these 2 groups of neurons do not reveal significant differences of the measured electrophysiological properties. Second, the depolarizing action of KA is not greatly affected by TTX and by low-calcium, cobalt-containing solutions, suggesting that postsynaptic mechanisms play a major role in the slow depolarization observed following acute application of KA. Third, kynurenate-sensitive receptors mediate not only the depolarizations produced by low doses of $\mathrm{K} \Lambda$, but also the acute neuronal degeneration caused by high doses of KA. Fourth, KA induces bicuculline-sensitive spontaneous depolarizing potentials that are probably caused by an increased release of endogenous GABA from depolarized terminals within the neostriatum.

\section{Differential neuronal sensitivity to $K A$}

The great majority of intracellularly recorded neostriatal neurons shows very homogeneous electrical properties (Kita et al., 1984; Calabresi et al., 1987a,b, 1988, 1989b, 1990b). Although in the present study, dye injection was not utilized to morphologically identify the recorded cells, previous staining studies have shown that the great majority of neostriatal neurons, intracellularly recorded in vivo and in vitro, are spiny neurons (Preston et al., 1980; Wilson and Groves, 1980; Lighthall and Kitai, 1983; Misgeld et al., 1984; Kawaguchi et al., 1989). A recent intracellular study has shown that an enormous sampling bias against the spiny neurons would be required to obtain a reasonable sample of aspiny cells from random sampling (Wilson et al., 1990). Despite their small size, neostriatal spiny neurons are relatively resistant to damage by microelectrodes, so there is no sampling bias against them that would facilitate recordings from aspiny neurons. In addition, it has been shown that large aspiny neurons present electrophysiological properties different from those observed in the cells selected in the present study (Wilson et al., 1990). Thus, the differential sensitivity to KA we observed seems to indicate the existence of 2 subpopulations of presumed spiny neurons showing different electrophysiological responses to KA, but not to NMDA and QUIS. Dye injections studies have to be carried out to directly verify this hypothesis.

The present results are consistent with several findings showing differential effects of excitotoxins in other areas of the CNS. Hippocampal pyramidal cells of CA3 and CA4 areas are particularly vulnerable to KA, while dentate granule cells are less sensitive (Kohler and Schwarcz, 1983; Ben Ari and Gho, 1988). On the other hand, ibotenic acid affects all cell types equally (Kohler and Schwarcz, 1983). In cerebellar slices in vitro, NMDA, QUIS, and KA show characteristic patterns of cellular degeneration (Garthwaite and Garthwaite, 1984). In the retina, differing patterns of cellular degeneration are caused by neurotoxins acting at different receptor subtypes (Olney et al., 1986; Morgan, 1987).

Recent studies show that some neurochemical markers of intrinsic striatal neurons are differentially affected by excitotox-
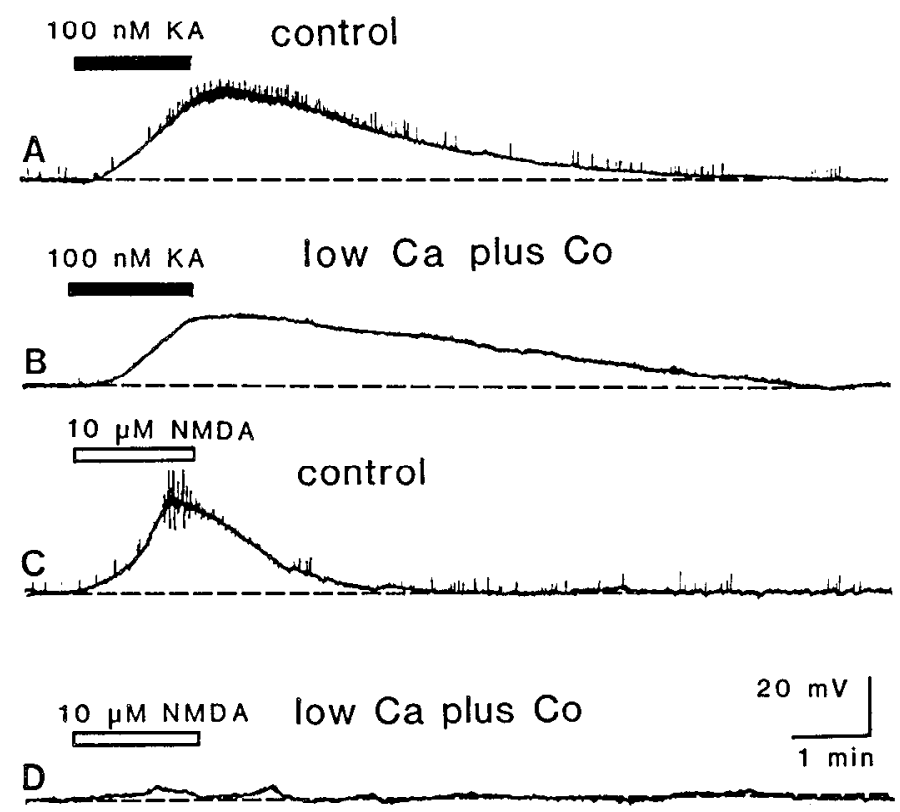

Figure 7. Low-calcium, cobalt-containing solution blocks NMDA-induced responses, but not those caused by KA. $A$, In the control condition, 100 nм $K A$ caused membrane depolarization coupled with an increase of the frequency of the spontaneous depolarizing potentials. $B$, In the presence of a low-calcium $(0.5 \mathrm{mM})$, cobalt-containing $(1.5 \mathrm{~mm})$ solution, the membrane response to $K A$ persisted, while the $\mathrm{KA}$-induced spontaneous depolarizing potentials were blocked. $C$, In the control condition, $10 \mu \mathrm{M} N M D A$ causcd large membranc depolarization. $D$, Low-calcium, cobalt-containing solution blocked the membrane responses to NMDA. All traces were recorded from the same cell (RMP, $-78 \mathrm{mV})$.

ins. A relative sparing of NADPH-diaphorase-containing neurons in response to NMDA agonists has been described (Koh et al., 1986; Koh and Choi, 1988; Choi, 1988). It has also been demonstrated that striatal large cholinergic neurons are relatively spared by KA (Araki et al., 1985; Beal et al., 1989). Although our data are not directly comparable with these morphochemical findings, it can be hypothesized that the differential electrophysiological responses we observed might result in different patterns of neuronal degeneration.

High-affinity KA binding sites were localized to the striatum and to field CA3 of the hippocampus several years ago (Monaghan and Cotman, 1982), but their physiological role has remained uncertain. Only a few other studies (e.g., Robinson and Deadwyler, 1981) have reported depolarizations to $<100 \mathrm{~nm}$ $\mathrm{KA}$. $\mathrm{EC}_{50}$ values near $100 \mathrm{~nm}$ have been found in most experiments in isolated cells (Kiskin et al., 1986), cultured neurons (Priestly et al., 1989), or receptors expressed in oocytes (Verdoorn and Dingledine, 1988).

Several reasons may account for the different responses to KA in the 2 subpopulations of cells of our study: (1) the different number of KA receptors present on the membrane of the recorded cells, (2) the existence of KA receptors showing differential affinity for this agonist, and (3) the different coupling between receptor activation and membrane ionic fluxes in these 2 subpopulations of cells (Ben-Ari, 1985; Coyle, 1987; Monaghan et al., 1989; Wroblewski and Danysz, 1989). Although our experiments do not distinguish between these hypotheses, they clearly show a close correlation between neurophysiologic potency and neurotoxic effects of KA. 
Figure 8. Antagonism of KA-induced responses by kynurenic acid. $A$, In the control condition, $100 \mathrm{~nm} K A$ produced a slow membrane depolarization. $B$, In the presence of $500 \mu \mathrm{M}$ kynurenic acid $(K Y)$, the $K A$-induced membrane response was reduced. $C$, After $15 \mathrm{~min}$ from the onset of the wash of kynurenic acid, the $K A$-induced depolarization recovered. $D$, The histograms show the KA-induced responses in the control condition (open columns) and in the presence of $500 \mu \mathrm{M}$ kynurenic acid (solid columns) during the application of either low $(0.1 \mu \mathrm{M}$, left columns) or high ( $1 \mu \mathrm{M}$, right columns) concentrations of KA. Bars indicate SEM; the numbers indicate the number of cells studied in each experimental condition. RMP was between -75 and $-82 \mathrm{mV}$.

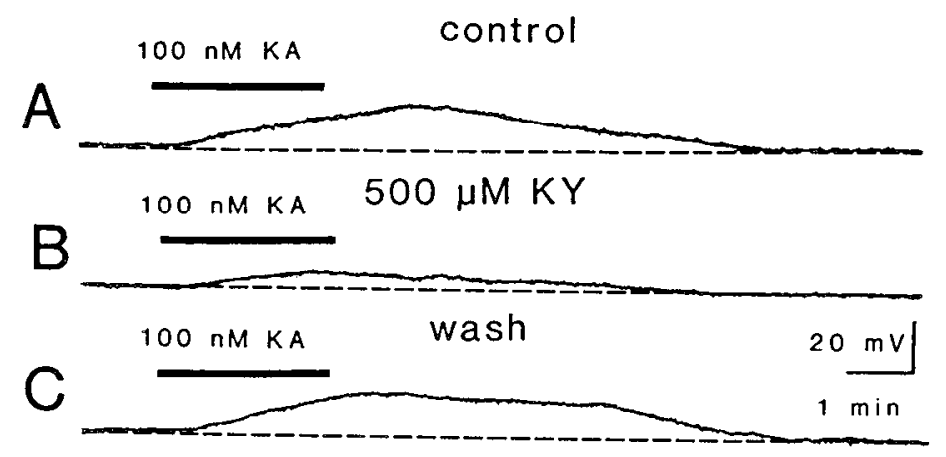

D

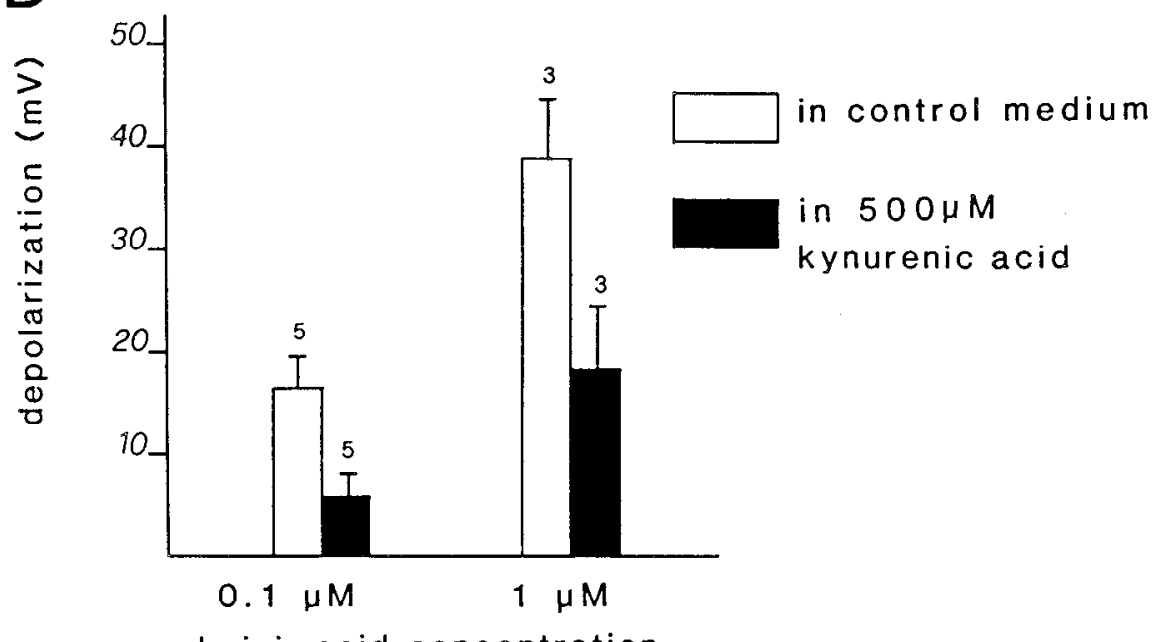

kainic acid concentration

\section{Postsynaptic mechanisms of $K A$ action}

The persistence of the KA-induced depolarizations in the presence of TTX and of low-calcium, cobalt-containing solutions shows that the effects observed following acute application of $\mathrm{KA}$ are mediated by postsynaptic mechanisms. A postsynaptic location of KA receptors is in agreement with previous studies, while a presynaptic location of KA binding sites is still controversial (for review, see Ben-Ari, 1985; Coyle, 1987; Greenamyre and Young, 1989). Lesions of the corticostriatal pathway confer a protection of neostriatal neurons from the toxic action of KA, suggesting that a presynaptic interaction between $\mathrm{KA}$ and an endogenous transmitter causes neural damage (McGeer et al., 1978). On the other hand, a recent binding study has suggested that KA receptor-recognition sites are almost exclusively located postsynaptically (Greenamyre and Young, 1989).

In most of the neostriatal neurons, KA induces depolarizations coupled with a decrease of membrane resistance. This effect, in contrast to the action of NMDA on these cells, is not blocked by low-calcium, cobalt-containing solutions. This finding suggests that in neostriatal slices, as well as in cultured central neurons (Mayer and Westbrook, 1987a,b; Ascher and Nowak, 1988), KA mainly activates sodium influx, while there is a much larger calcium flux through NMDA- than through KA-activated channels. In a few neurons, during application of low concentrations of KA, we observed a slight increase of the membrane resistance; this finding can be related to a possible KA-induced decrease of potassium conductances as previously described in hippocampal neurons (Gho et al., 1986). In the CA3 hippocampal arca, KA induced cpilcptic activity characterized by spontaneous and evoked bursts of action potentials and paroxysmal depolarizing shifts followed by long-lasting afterhyperpolarizations (Ben-Ari and Gho, 1988). This bursting behavior was never observed in neostriatal neurons, even during application of KA concentrations causing permanent neuronal damage. Two main reasons may account for the lack of epileptic activity in the neostriatum: (1) In the neostriatum, the recurrent excitation, at least in vitro, is too sparse to trigger synchronous bursts (Calabresi et al., 1989b), and (2) neostriatal neurons do not possess, under control conditions, prominent calcium conductances and slow calcium-mediated potassium afterhyperpolarizations (Calabresi et al., 1987a,b, 1988, 1990b).

\section{Neurotoxic effects of $K A$ are receptor mediated}

Kynurenic acid reduced the membrane effects caused by low concentrations of KA and blocked the changes of the electrical neuronal activity induced by high doses of this glutamate analog. This observation suggests that receptor-mediated mechanisms underlie either the physiological responses to KA or the toxic effects of KA on neostriatal neurons. In the past, indirect mechanisms have been postulated for the neurotoxic action of KA. Acute metabolic alterations, such as ischemia, increase in glucose utilization, accumulation of internal calcium, and increase 


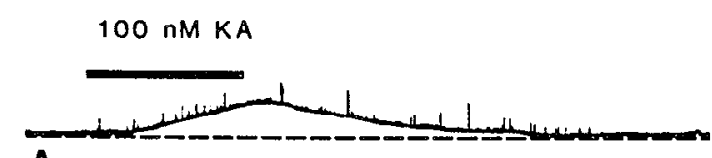

A

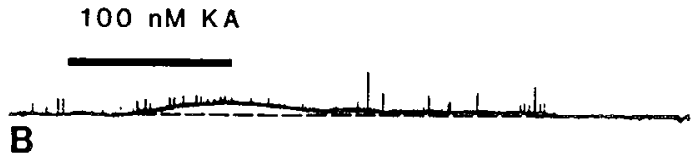

B
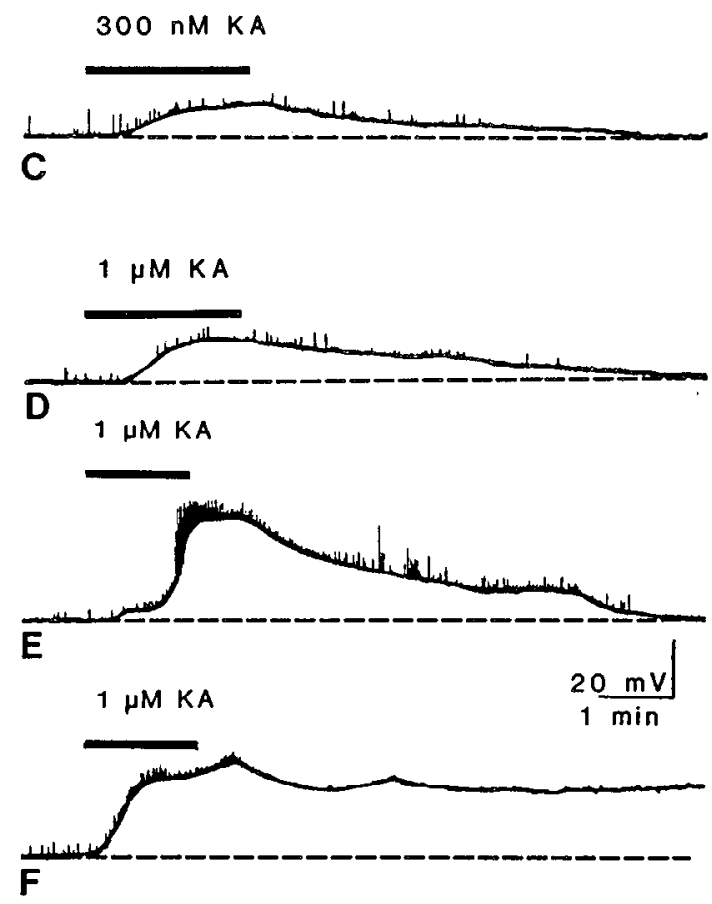

in extracellular potassium coupled with impaired glial uptake, have been implicated in the so-called "nonspecific mechansisms of KA toxicity" (for review, see Ben-Ari, 1985; Coyle, 1987). However, recent increasing evidence shows that receptor-operated mechanisms mediate most of the metabolic changes underlying KA toxicity (Coyle, 1987; Monaghan et al., 1989; Wroblewski and Danysz, 1989). A further indication, that the KA-induced toxicity is not simply caused by nonspecific membrane depolarization, is the evidence that the increase of the external potassium concentration, up to reaching the same depolarized membrane potentials obtained during the application of high concentrations of KA, does not cause irreversible electrical changes in neostriatal neurons (P. Calabresi, unpublished observations).

\section{KA induces bicuculline-sensitive synaptic potentials}

Most neostriatal neurons are GABA-containing cells (Groves, 1983); GABA is not only relcased from axon terminals in the output structures, but it is also used as a transmitter in the neostriatum itself (Groves, 1983; Lighthall and Kitai, 1983; Calabresi et al., 1990a,b). Spontaneous bicuculline-sensitive depolarizing potentials have been described in neostriatal neurons at resting level (Calabresi et al., 1990b). Bicuculline-sensitive depolarizing potentials were greatly enhanced in frequency and

\section{control}

$500 \mu \mathrm{M} \mathrm{KY}$

$500 \mu \mathrm{M} \mathrm{KY}$

$500 \mu \mathrm{M} \mathrm{KY}$

5 min wash

15 min wash
Figure 9. Kynurenic acid blocks irreversible miembrane depolarization produced by high concentrations of KA. $A$, Under the control condition, $100 \mathrm{~nm}$ $K A$ produced a slow membrane depolarization. $B$. The membrane response to $100 \mathrm{~nm} K A$ was reduced in the presence of $500 \mu \mathrm{M}$ kynurenic acid $(K Y) . C$, Membrane response to $300 \mathrm{nM} K A$ in the presence of $500 \mu \mathrm{M}$ kynurenic acid. $D$, In the presence of kynurenic acid, 1 $\mu \mathrm{M} K A$ produced a reversible membrane depolarization. $E$, Five min after the onset of the wash of kynurenic acid, $1 \mu \mathrm{M} K A$ caused a membrane response much larger than that observed in the presence of the antagonist. $F$, Fifteen min after the onset of the wash of kynurenic acid, $1 \mu_{\mathrm{M}} K A$ produced an irreversible neuronal depolarization. All traces were recorded from the same cell (RMP, $-80 \mathrm{mV}$ ).

amplitude during the application of KA. KA induced depolarizing potentials even in cells showing no spontaneous synaptic activity under control conditions. The finding that these KAinduced spontaneous depolarizations were fully blocked by lowcalcium, cobalt-containing solutions and greatly reduced by TTX shows that they are synaptically mediated. The decrease of these potentials in the presence of bicuculline suggests that they are caused by endogenous GABA.

Although previous biochemical studies reported KA-induced GABA release from neostriatal (Pin and Bockaert, 1989), hippocampal (Harris and Miller, 1989), and cerebellar (Gallo et al., 1987) cultured neurons, this is the first physiological evidence showing $\mathrm{KA}$-induced GABA release in the neostriatum.

\section{Physiological and clinical implications}

The differential sensitivity of neostriatal neurons to KA might have both physiological and clinical implications. The corticostriatal projection provides the main excitatory input to the neostriatum; glutamate plays a major role in this pathway (Divac et al., 1977; Reubi and Cuenod, 1979). It has been shown that kynurenic acid blocks cortically evoked excitatory synaptic potentials in the neostriatum (Walsh et al., 1989), and QUIS and $\mathrm{KA}$ receptors have been implicated in the generation of these potentials (Herrling, 1985). For this reason, it is likely that 

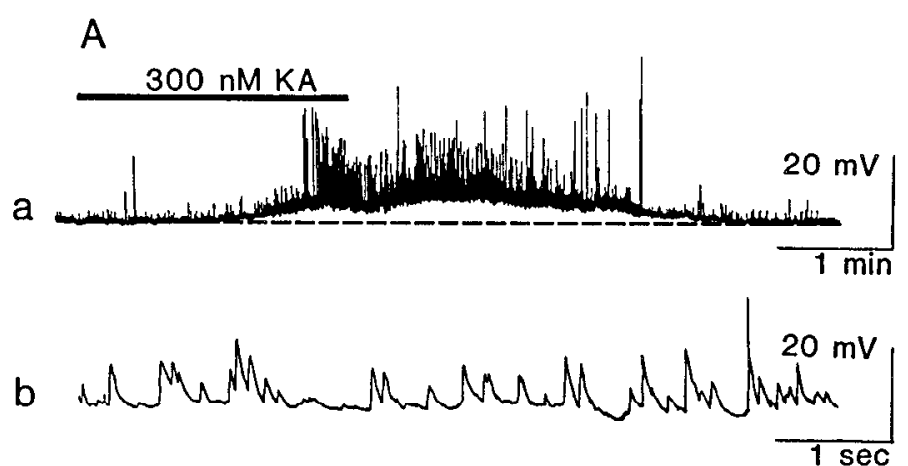

B

$300 \mathrm{nM} \mathrm{KA} \quad$ in $100 \mu \mathrm{M}$ bicuculline

a1

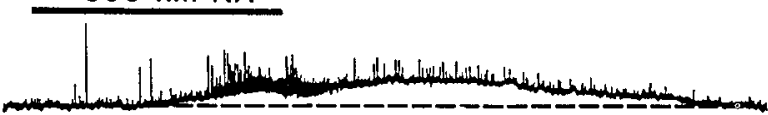

b1

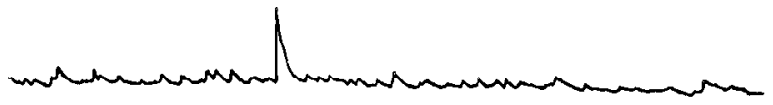

Figure 10. KA induces bicuculline-sensitive synaptic depolarizing potentials. $A a$, In the control condition, $300 \mathrm{nM} K A$ caused a slight depolarization coupled with an increase of the frequency of spontaneous depolarizing potentials (this cell showed a low postsynaptic sensitivity to KA). $A b$, The spontaneous depolarizing potentials are shown at higher speed. $B a$, One-hundred $\mu \mathrm{M}$ bicuculline did not affect the membrane response to $K A$, hut clearly reduced the amplitude and the frequency of the KA-induced spontaneous depolarizing potentials. $B b$. The KA-induced spontaneous potentials in the presence of bicuculline are shown at higher speed. All traces were recorded from the same cell. Calibration bars in $A a$ and $A b$ also apply to $B a$ and $B b$.

the differential postsynaptic sensitivity of neostriatal neurons to KA may influence the characteristics of the synaptic responses following cortical activation.

Postmortem studies have revealed significant losses of ${ }^{3} \mathrm{H}-$ $\mathrm{KA}$ and ${ }^{3} \mathrm{H}$-glutamate receptors in the caudate and putamen of patients affected by Huntington's disease (Greenamyre et al., 1985; Coyle, 1987), indicating that neurons enriched in these receptors are affected in the neuronal degeneration observed in this pathology. We have shown that the neurotoxic effects of KA on neostriatal neurons are caused by receptor-mediated mechanisms. For this reason, pharmacological modulation of electrical responses to KA in vitro will provide some information concerning the possible use of novel agents in the therapy of Huntington's disease.

\section{References}

Araki M, McGeer PL, McGeer EC (1985) Differential effects of kainic acid on somatostatin, GABAergic and cholinergic neurons in the rat striatum. Neurosci Lett 53:197-202.

Ascher P, Nowak L (1988) Quisqualate- and kainate-activated channels in mouse central neurones in culture. J Physiol (Lond) 399:227245.

Beal MF, Kowall NW, Ellison DW, Mazurek MF, Swartz KJ, Martin JB (1986) Replication of the neurochemical characteristics of Huntington's disease by quinolinic acid. Nature 321:168-171.

Beal MF, Kowall NK, Swartz KJ, Ferrante RJ, Martin JB (1989) Differential sparing of somatostatin-neuropeptide $Y$ and cholinergic neurons following striatal excitotoxic lesions. Synapse 3:38-47.

Ben-Ari Y (1985) Limbic seizures and brain damage produced by kainic acid: mechanisms and relevance to human temporal lobe epilepsy. Neuroscience 14:375-403.
Ben-Ari Y, Gho M (1988) Long-lasting modification of the synaptic properties of rat CA3 hippocampal neurons induced by kainic acid. J Physiol (Lond) 404:365-384.

Calahresi P, Misgeld U, Dodt U (1987a) Intrinsic membrane properties of neostriatal neurons can account for their low level of spontaneous activity. Neuroscience 20:293-303.

Calabresi P, Mercuri NB, Stanzione P, Stefani A, Bernardi G (1987b) Intracellular studies on the dopamine-induced firing inhibition of neostriatal neurons in vitro: evidence for D1 receptor involvement. Neuroscience 20:757-771.

Calabresi P, Benedetti M, Mercuri NB, Bernardi G (1988) Endogenous dopamine and dopaminergic agonists modulate synaptic excitation in neostriatum: intracellular studies from naive and catecholamine depleted rats. Neuroscience 27:145-157.

Calabresi P, Lacey MG, North RA (1989a) Nicotinic excitation of rat ventral tegmental neurones in vitro studied by intracellular recording. Br J Pharmacol 98:135-140.

Calabresi P, Benedetti M, Mercuri NB, Bernardi G (1989b) Selective depression of synaptic transmission by tetanus toxin: a comparative study on hippocampal and neostriatal slices. Neuroscience 30:663670.

Calabresi P, Mercuri NB, Stefani A, Bernardi G (1990a) Synaptic and intrinsic control of membrane excitability of neostriatal neurons. I. An in vivo analysis. J Neurophysiol 63:651-662.

Calabresi P, Mercuri NB, Bernardi G (1990b) Synaptic and intrinsic control of membrane excitability of neostriatal neurons. II. An in vitro analysis. J Neurophysiol 63:663-675.

Choi DW (1988) Glutamate neurotoxicity and diseases of the nervous system. Neuron 1:623-634.

Coyle JT (1983) Neurotoxic action of kainic acid. J Neurochem 41: $1-11$.

Coyle JT (1987) Excitotoxins. In: Psychopharmacology: the third generation of progress (Melzer HY, ed), pp 333-340. New York: Raven.

Coyle JT, Schwarcz R (1976) Lesion of striatal neurones with kainic acid provides a model for Huntington's chorea. Nature 263:244-246.

Coyle JT, Molliver MR, Kuhar MJ (1978) In situ injection of kainic acid: a new method for selectively lesioning neuronal cell bodies while sparing axons of passage. J Comp Neurol 180:301-318.

Divac I, Fannum F, Storm-Mathisen J (1977) High affinity uptake of glutamate in terminals of corticostriatal axons. Nature 266:377-378.

Ferkany JW, Zaczek R, Coyle JT (1982) Kainic acid stimulates excitatory amino acid neurotransmitter release at presynaptic receptors. Nature 298:757-759.

Ferrante RJ, Kowall NW, Beal MF, Richardson EP, Martin JB (1985) Selective sparing of a class of striatal neurons in Huntington's disease. Science 230:561-563.

Gallo V, Suergiu R, Giovannini C, Levi G (1987) Glutamate receptor subtypes in cultured cerebellar neurons: modulation of glutamate and $\gamma$-aminobutyric release. J Neurochem 49:1801-1809.

Garthwaite G, Garthwaite J (1984) Differential sensitivity of rat cerebellar cells in vitro to the neurotoxic effects of excitatory amino acid analogues. Neurosci Lett 48:361-367.

Gho M, King AE, Ben-Ari Y, Cherubini E (1986) Kainate reduces two voltage-dependent potassium conductances in rat hippocampal neurons in vitro. Brain Res 385:411-414.

Greenamyre JT, Young AB (1989) Synaptic localization of striatal NMDA, quisqualate and kainate receptors. Neurosci Lett 101:133137.

Greenamyre JT, Penney JB, Young AB, D'Amato C, Hicks SP, Shoulson I (1985) Alterations in $\left.\mathrm{L}-{ }^{3} \mathrm{H}\right]$ glutamate binding in Alzheimer's and Huntington's diseases. Science 227:1496-1499.

Groves PM (1983) A theory of the functional organization of the neostriatum and the neostriatal control of voluntary movement. Brain Res Rev 5:109-132.

Harris KM, Miller RJ (1989) Excitatory amino acid-evoked release of $\left[{ }^{3} \mathrm{H}\right]$ GABA from hippocampal neurons in primary culture. Brain Res 482:23-33.

Herrling PL (1985) Pharmacology of the corticocaudate excitatory post-synaptic potential in the cat: evidence for its mediation by quisqualate-or kainate-receptors. Neuroscience 14:417-426.

Kawaguchi Y, Wilson CJ, Emson PC (1989) Intracellular recording of identified neostriatal patch and matrix spiny cells in a slice preparation preserving cortical inputs. J Neurophysiol 62:1052-1068.

Kiskin NI, Krishtal OA, Tsyndreko AY (1986) Excitatory amino acid receptors in hippocampal neurons: kainate fails to desensitize them. Neurosci Lett 63:225-230. 
Kita T, Kita K, Kitai ST (1984) Passivc clcctrical membrane properties of rat neostriatal neurons in vitro slice preparation. Brain Res 300 : 129-139.

Koh JY, Choi DW (1988) Cultured striatal neurons containing NADPH-diaphorase or acetylcholinesterase are selectively resistant to injury by NMDA receptor agonists. Brain Res 446:374-378.

Koh JY, Peters S, Choi DW (1986) Neurons containing NADPHdiaphorase are selectively resistant to quinolinate toxicity. Science 234:73-76.

Kohler C, Schwarcz R (1983) Comparison of ibotenate and kainate neurotoxicity in rat brain: an histological study. Neuroscience 8:819835.

Lighthall JW, Kitai ST (1983) A short duration GABAergic inhibition in identified neostriatal medium spiny neurons: in vitro slice study. Brain Res Bull 11:103-110.

Mayer ML, Westbrook GL (1987a) Permeation and block of $N$-methyl-D-aspartic acid receptor channels by divalent cations in mouse cultured central neurones. J Physiol (Lond) 394:501-527.

Mayer ML, Westbrook GL (1987b) The physiology of excitatory amino acids in the vertebrate central nervous system. Prog Neurobiol 28: 197-276.

McGeer EG, McGeer PL (1976) Duplication of biochemical changes of Huntington's chorea by intrastriatal injections of glutamic acid and kainic acids. Nature 263:517-519.

McGeer EG, McGeer PL, Singh K (1978) Kainate induced degeneration of neostriatal neurones: dependency on cortico-striatal tract. Brain Res 139:381-383.

Misgeld U, Frotscher M, Wagner A (1984) Identification of projecting ncurons in rat ncostriatal sliccs. Brain Res 299:367-370.

Misgeld U, Calabresi P, Dodt U (1986) Muscarinic modulation of calcium dependent plateau potentials in rat neostriatal neurons. Pfluegers Archiv 407:482-487.

Monaghan DT, Cotman CW (1982) The distribution of ${ }^{3} \mathrm{H}$ kainic acid binding sites in rat CNS as determined by autoradiography. Brain Res 252:91-100.

Monaghan DT, Bridges RJ, Cotman CW (1989) The excitatory amino acid receptors: their classes, pharmacology, and distinct properties in the function of the central nervous system. Annu Rev Pharmacol Toxicol 29:365-402.

Morgan IG (1987) AMPA is a powerful neurotoxin in the chicken retina. Neurosci Lett 78:267-271.
Olney JW, Price MT, Fuller TA, Labruyere J, Samson L, Carpenter M, Mahan K (1986) The anti-excitotoxic effects of certain anesthetics, analgesics and sedative-hypnotics. Neurosci Lett 68:29-34.

Pin JP, Bockaert J (1989) Two disintct mechanisms, differentially activated by excitatory amino acids, trigger GABA release from fetal mouse striatal neurons in primary culture. J Neurosci 9:648-656.

Preston RJ, Bishop GA, Kitai ST (1980) Medium spiny from rat striatum: an intracellular horseradish peroxidase study. Brain Res 185:253-263.

Priestley T, Woodruff GN, Kemp JA (1989) Antagonism of responses to excitatory amino acids on rat cortical neurones by the spider toxin, argiotoxin 636. Br J Pharmacol 97:1315-1323.

Reubi JC, Cuenod M (1979) Glutamate release in vitro from corticostriatal terminal. Brain Res 176:185-188.

Robinson JH, Deadwyler SA (1981) Kainic acid produces depolarization of CA3 pyramidal cells in the in vitro hippocampal slice. Brain Res 221:117-127.

Schwarcz R, Scholcz D, Coyle JT (1978) Structure activity relations of the neurotoxicity of kainic acid derivatives and glutamate analogues. Neuropharmacology 17:145-151.

Verdoorn TA, Dingledine R (1988) Excitatory amino acid receptors expressed in Xenopus oocytes: agonist pharmacology. Mol Pharmacol 34:298-307.

Walsh JP, Hull CD, Levine MS, Buchwald NA (1989) Kynurenic acid antagonizes the excitatory postsynaptic potential elicited in neostriatal neurons in the in vitro slice of the rat. Brain Res 480:290-293.

Wilson CJ, Groves PM (1980) Fine structure and synaptic connections of the common spiny neuron of the rat neostriatum. A study employing intracellular injection of horseradish peroxidase. J Comp Neurol 194:599-615.

Wilson CJ, Chang HT, Kitai ST (1990) Firing patterns and synaptic potentials of identified giant aspiny interneurons in the rat neostriatum. J Neurosci 10:508-519.

Wroblewski JT, Danysz W (1989) Modulation of glutamate receptors: molecular mechanisms and functional implications. Annu Rev Pharmacol Toxicol 29:441-474.

Zaczek R, Coyle JT (1982) Excitatory amino acid analogues: neurotoxicity and seizures. Neuropharmacology 21:15-26. 